\title{
Application of the Naturally Optimised Revenue Demand in Communities NORDIC Model to Improve the Education in Sweden
}

\author{
Jan Stenis \\ Kristianstad, Sweden \\ Email: jan.stenis@icloud.com
}

How to cite this paper: Stenis, J. (2020). Application of the Naturally Optimised Revenue Demand in Communities NORDIC Model to Improve the Education in Sweden. Theoretical Economics Letters, 10, 523-534. https://doi.org/10.4236/tel.2020.103033

Received: April 11, 2020

Accepted: May 24, 2020

Published: May 27, 2020

Copyright $\odot 2020$ by author and Scientific Research Publishing Inc. This work is licensed under the Creative Commons Attribution International License (CC BY 4.0).

http://creativecommons.org/licenses/by/4.0/

\begin{abstract}
The Naturally Optimised Revenue Demand in Communities (NORDIC) model was employed to improve the education. Dropout is a serious problem. It affects not only the individual who drops out but also the university and society. This article introduced a new and practical economic instrument for improved management of dropouts, based on the NORDIC model. The proposed model produced constructed shadow costs to be inserted into the public accounts to induce economic incentives to decrease the dropout rate. The resulting shadow cost, and its impact on the PSBR, constitutes a single key factor that, by one digit only, expresses how successful the education policy is over time. The launched model considered the age of students who pass a BSc. This case study showed how education in the Swedish society could be improved by application of the NORDIC model, that is the system of cooperation between students and government. The results point at a promising methodology for reducing the dropout rate and decreasing the qualification age by using economic instruments. The study concludes that the NORDIC model could be used to improve the Swedish education system and its qualification age, particularly for BScs. Governments obtain a tool to monitor, manage and evaluate the education sector. Possible end users include school authorities and politicians that want a comprehensive tool to redesign the education policy. The NORDIC model is recommended to apply to education issues to lower the qualification age. Further research focuses on developing algorithms for certain categories of students.
\end{abstract}

\section{Keywords}

Education, Dropout Rate, Economic Instrument 


\section{Introduction}

Much attention has been devoted to the dropout issue. University dropout is a serious problem. It affects not only the individual who drops out but also the university and society (Kim \& Kim, 2018). Dropping out means leaving high school, college or university for practical reasons, necessities or disillusionment. Students that drop out of high school are generally those that struggle to engage behaviorally and/or academically (Dropping Out, 2020). This paper aims to address the nations' dropout-burden. The objective of this study was to launch a new and practical method of improving the education by designing a decision-support tool for authorities, politicians and other citizens interested in education policy to facilitate the daily use of the Naturally Optimised Revenue Demand in Communities, NORDIC model (Stenis, 2020a, 2020b; Stenis \& Hogland, 2019). The hypothesis of this work was that the flow of students through nations' education authorities could be improved by applying the NORDIC model. The research question was whether the education could actually be improved by employing economic instruments and whether this approach was feasible. The research was focused on accomplishing a change. The method selected was case studies of stakeholders to obtain information. An analytical approach was used. The research design featured a logical approach in a historical context. This design supported the hypotheses that the logic was inherent in the mathematics employed by the NORDIC model, and backed up by historical data; a quantitative research methodology was predominant. The theoretical implication of the study was the achievement of an enhanced scientific background in decision-making. The provided tool expanded the theoretical knowledge.

The background and motivation for conducting the study was given. The theory for the NORDIC model is outlined, followed by a description of how to use it. The case study shows how the education in the Swedish society can be improved by application of the model, followed by the results and discussion, conclusion, benefits of the proposed model, and recommendations for authorities and politicians. Relevant know-how was accumulated. The practical implications of this study were better circumstances for the students and enhanced opportunities for leaders to logically explain reasons for initiating certain actions, other than based on emotional causes. The research gap that this study could fill is the need for new economic instruments to manage the education sector. The study could contribute to improving the economy, which in turn would improve the living conditions in communities.

\section{Review of the Literature}

A review of works by other scholars on education, dropouts, shadow costs and models were done. In reversed, chronological order, the review showed that Gupta, Antony, Lacher, and Douglas (2020) investigated the causes behind student dropouts in higher education institutions (HEIs) and explored the use of Lean Six Sigma (LSS) tools in reducing dropout rates and found that HEIs have 
to maintain detailed records and sensitize relevant authorities about the impact of a student's dropout decision. Gray and Perkins (2019) examined the literature surrounding methods and measures in use in Learning Analytics and found they do not focus on earliest possible identification of struggling students, created a predictive model for student outcomes and demonstrated how students can be identified as early as week 3 of the Fall semester with approximately $97 \%$ accuracy. Perchinunno, Bilancia, and Vitale (2019) showed that the most significant indicator for assessing the quality of university careers is the dropout rate between the first and second year and were able to identify the profile of students who are most likely to dropout. Periwal and Rana (2017) compared Massive Open Online Courses (MOOCs) and found that for the success of MOOCs, their dropout rates must decrease, created four models and found that the model created by Naïve Bayes technique performed well for imbalance class data of MOOCs. Iemmi et al. (2015) reviewed systematically Community-Based Rehabilitation to promote the inclusion of people with disabilities, particularly in low- and middle-income countries, to assess the cost-effectiveness. Fedorov (2014) demonstrated that the most typical synthetic models for prospective media literacy education, used in the process of education and upbringing, belong to three groups. Wankel, Blessinger, Stanaityte, and Washington (2013) examined new research on how increasing student engagement and retention using classroom technologies response systems, and mediated discourse technologies, are being used in higher education to increase learner engagement in an epoch of increasing globalization and diversity. Fedorov (2011) supposed that media education models can be divided into groups: 1) educational-information models; 2) educational-ethical models; 3) pragmatic models; 4) aesthetical models; and 5) socio-cultural models. Noh, Lee, and Kenward (2011) estimated dropout models using hierarchical likelihood. de Bruin, Smits, Rikers, and Schmidt (2008) examined the longitudinal relation between deliberate practice and performance in chess and revealed that serious chess study alone and serious chess play strongly contributed to chess performance, also over chess players' careers. Budgen and Gamroth (2008) made an overview of practice education models for nursing students to improve the practice education and found that emerging developments in practice education are increased inter-professional and community-based practice education, and new partnerships among academic and practice organizations. Morphew and Baker (2007) presented the results of a research study on resource cost models in higher education to construct and examine a model that estimates relative faculty instructional costs for specific undergraduate degree programs and identified differences in these costs by region and institutional type. Csermely, Korlevic, and Sulyouk (2006) told why to engage in scientific education of talented students as early as possible to develop the critical minds or scientific method judgments, stating that most of them work in isolation, often struggling with lack of resources and stay unrecognized to the general public. Longden and Mantz (2004) studied the retention and student success in higher education and found that government and the HE sector 
have woken up to the implications for public finance and equity of students not completing their studies. Verzilli and Carpenter (2002) proposed a Monte Carlo version of the EM algorithm because longitudinal studies of neurological disorders suffer almost inevitably from non-compliance, which is likely to be non-ignorable, and found that it is important in these cases to model the response variable and the dropout mechanism jointly. Napoli and Wortman (1998) assessed the validity of a model to extend and refine the model, confirmed the generalizability of the model to two-year community college populations and revealed that the psychosocial measures have both direct and indirect effects on college persistence. Beckne (1995) investigated the dropping out and found that many reasons should be considered symptoms rather than real causes as the earlier the dropout happens, more patterns of psychological, social and academic failure and disengagement are observed. Horowitz (1992) reported on dropouts to identify a dropout before the act of leaving school and found that the dropouts scored more positively on the self-estrangement, meaninglessness, and misfeasance scales while in the academic school, the dropouts scored positively on the anxiety scale.

The present study takes these and other aspects of school policy into account because its' approach uses currency to express relevant education-factors. There are no approaches similar to the present that simultaneously reduce the dropout rate and decrease the qualification age by just a single key factor, like the NORDIC model does.

\section{Research Methods}

The basis for this work was the existing NORDIC model (Stenis, 2020a, 2020b; Stenis \& Hogland, 2019). The components of the NORDIC model were studied and adapted to education issues.

\subsection{The Subjects}

The new approach was tested on the students in Sweden in a case study with real-world facts and figures. The nation of Sweden was chosen because it offers an extensive tradition of powerful school authorities that provide a wealth of data relevant to this study.

\subsection{The Study Procedures}

\subsubsection{Experimental Interventions}

Other than personal computers, no mechanical apparatus was used due to the detached approach selected by the author. Therefore, no direct intervention was administered.

\subsubsection{Sampling Procedures, Sample Size and Ethical Considerations}

The plan was to find data that was most recent as well as reliable. Data was collected from public sources on the internet. No agreements or payments were made to obtain this information. The sample size was 298,668 students in Swe- 
den 2018 (Statistics Sweden [SCB], 2020a).

No agreements were made with any institutional review-board. Ethical standards were met because no living individuals or animals were directly involved in the study, requiring no physical safety monitoring procedures.

\subsubsection{Measurement Approaches}

The methods used to collect data consisted of observations of relevant study-groups from online sources. The reliability of the observations was established by only consulting reliable sources on the internet. Evidence of cultural validity was based on the use of mainly impersonal, socio-economic data.

\subsubsection{The Research Design}

The introduction provides the background and motivation for conducting the study from a scientific point of view. The theory for the NORDIC model has been outlined. This will be followed by a description of how to use the NORDIC model for education policy issues in the analysis section below. Thereafter, a case study to illustrate how the NORDIC model in practice can reduce the dropout rate in the nation of Sweden is presented. This exemplification is followed by the results and discussion, conclusion, benefits of the proposed model, and recommendations for authorities and politicians.

\subsection{Theory Foundation}

The NORDIC model gives a shadow cost (Shadow Price, 2020) that mirrors the development of the study object.

$$
S=(X / Y) * \sum Z * W=\left[\left(\sum V-\sum C\right) / Y\right] * \sum Z * W
$$

where

$S$ is the Shadow cost to be additionally inserted in the accounts of the organization; $X$ is the phenomenon to be optimized $=V-C(V$ is the Value of $X ; C$ is the Cost of $X$ ); $Y$ is the total value of the organization; $Z$ is the value of the entities connected to $X ; W$ is the Weight factor for the general impact of $X$ on society, during a certain period in a certain, administrative unit.

Possible sorts to apply are USD, kilogram, liter or Joule. The $W$ factor has no sort, it is a decimal number.

\subsection{Application of the NORDIC Model to Education}

The economic aspect is featured as regards education. The Nordic model gives a shadow cost that mirrors how successfully the dropout rate is reduced.

$$
S_{\text {droput }}=((V-C) / G) * L * A
$$

where

$S_{\text {dropout }}$ is the Shadow cost for dropouts in a nation; $X$ is all the students of the nation $=V-C ; V$ is the total economic Value of the nation's students on the labor market; $C$ is the total national education budget; $G$ is the GDP of the nation; 
$L$ is the total cost for study Loans in extraordinary circumstances, after the studies' nominal period of loan, in the nation; $A$ is the Average age for passing a Bachelor of Science (BSc) in the nation. Period: annually. Sort: US dollars.

Table 1 shows the principle for the use of the shadow cost $S_{\text {dropout }}$ (Ekonomifakta, 2020a). In this example, the shadow cost $S_{\text {dropout }}$ is added to nations' expenses, the parameter $L$ being a cost that negatively impacts the result.

General decision rules: $A$ reduced PSBR due to a decreasing $S_{\text {dropout }}$ cost over time points at a more successful school system than before. $A$ raised PSBR due to an increased $S_{\text {dropout }}$ cost calls for action to improve the education-policy.

However, the NORDIC model does not provide the very means and measures to implement. It gives management an indication of the dropout-status, as a decision-basis for how powerful tools to employ, but not precisely which.

\subsection{Analysis}

$A$ decreased Public Sector Borrowing Requirement (PSBR), due to a lowered $S_{\text {dropout }}$, points to a more successful education policy. If the PSBR increases over time due to a raised $S_{\text {dropout }}$, this calls for action by school authorities.

\subsection{Manual for Practical Application of the NORDIC Model to Education}

The following steps are used when applying the NORDIC model to education issues.

1) Estimate the value of the parameters in Equation (2) by consulting public information sources.

2) Calculate the constructed shadow cost $S_{\text {dropout }}$.

3) Regularly estimate the parameters in Equation (2).

4) Regularly calculate $S_{\text {dropout }}$ to follow its development over time.

5) Take actions if $S_{\text {dropout }}$ increases to decrease the dropout rate.

Several parties, e.g. relevant school authorities, should collaborate to use the NORDIC model. Subsequently, the dropout rate and the qualification age can easily be lowered in nations where the NORDIC model is applied.

\subsection{Case Study: Application of the NORDIC Model to Swedish Education in 2018}

$X=V-C$ given by the Swedish costs for the educational system was USD 36 billion (SEK 360404 million) (SCB, 2020a).

Table 1. The nation's public budget.

\section{Revenues}

Expenses $S_{\text {dropout }}$

Public Sector Borrowing Requirement (PSBR) 
$G$ by the Swedish GDP was USD 483 billion (SEK 4834 billion) (SCB, 2020b).

$L$ by the Swedish costs for study Loans in extraordinary circumstances, after 6 years of study, was USD 2.7 million (SEK 26.5 million) (CSN, 2020).

$A$ by the average Age for Swedes qualifying for a BSc exam was 28 years (Ekonomifakta, 2020b).

An exchange rate of USD1 = SEK10 (February 2020) was used for this case study.

Equation (2) gives:

$$
S_{\text {droput }}=(36 \text { billion } / 483 \text { billion }) * 2.7 \text { million } * 28=\text { USD5.6 million }
$$

$S_{\text {dropout }}=$ was added to the public budget of Sweden. Table 2 shows the impact of the constructed cost $S$ on the public finances of the nation of Sweden. $S_{\text {dropout }}$ was inserted in the table as an expense, due to be a cost.

An increased PSBR by approximately USD6 million led to actions by the Swedish school authorities to improve the education. If the next estimation of $S_{\text {dropout }}$ showed a lower shadow cost, it pointed out that Sweden had become better at reducing the dropout rate and lowering the qualification age. Actions would then be taken based on repeated estimations of $S$.

\subsection{Sensitivity Analysis of the Proposed Theory}

Figure 1 shows how the resulting shadow cost $S$ varies with the main parameter $L$ when the NORDIC model is applied to the Swedish students. On the abscissa, input variables around the $L$-value MUSD2.7 in Equation (3) are displayed. The ordinate shows the results produced by Equation (3) for different $L$-values around MUSD2.7. The relationship is linear, illustrating that the proposed theory provides a stable outcome regardless of input.

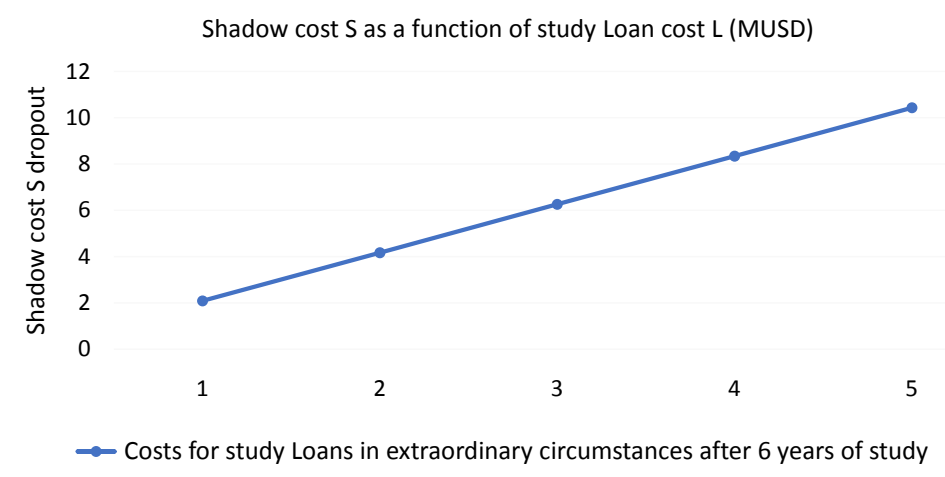

Figure 1. Relationship between the shadow cost and the study loan cost when applying the NORDIC model.

Table 2. The public budget of Sweden considering the shadow cost $S$ of dropouts.

\begin{tabular}{c} 
Revenues \\
Expenses $S_{\text {dropout }}=$ MUSD5.6 \\
PSBR $+S_{\text {dropout }}=$ PSBR + MUSD5.6 \\
\hline
\end{tabular}




\section{Results and Discussion}

The objective of this paper was to launch a new and practical method to improve the education. A review of similar literature showed that this objective was been accomplished as a decision-support tool has been provided for use by school authorities, politicians and citizens interested in education policy. The $L$ factor in Equation (2) was successfully employed in case studies selected to value the dropout rate of the students in Sweden. The age-factor $A$ promoted healthier students overtime due to the shadow cost $S_{\text {dropout }}$ decreasing with a larger number of qualified persons, and hence a more productive population. According to Table 1, PSBR decreases, which is favorable.

The main goal was to facilitate the daily use of the NORDIC model by school authorities and education managers. This goal was met by successfully adapting the NORDIC model to education issues in this paper, shown by the mathematical accuracy of the revised, and easy to use, model. The authenticity of the case study supports this statement. The hypothesis of this work was that the flow of students through nations' education systems could be improved by applying the NORDIC model. This was proven by the mathematical logics and the fidelity of the case study illustrating usefulness of the NORDIC model for these purposes. The case studies produced realistic and reliable results regarding improvement of the education in a nation. The scientific problem and question to be solved and answered were if the education actually could be improved by employing economic instruments? Was that approach feasible or not? The useful design of the developed equation and the promising possibility to apply the shadow cost-approach to the education sector, provide an affirmative response.

The case study exhibited a reasonable shadow cost of about USD6 million. This promising result points at the utility of the proposed methodology in practice. Thus, the general objective to provide school authorities with a useful tool was fulfilled. This model is hinged on its consideration for the economy and quality of life of the nation's students.

Politicians and other concerned parties are provided with a practical tool to be used over time to study the development of their nation's study-quality. This improves the economy and welfare and reduces human suffering.

The NORDIC model does not determine in detail which solutions to implement. It provides managers with an overview of a general picture of the prevailing situation. This is how economic instruments work. The NORDIC model also includes a stepwise, practical manual presented in section 3.6 that gives a quick introduction on how the NORDIC model is used.

The disadvantage of this model is its inaccuracy in pinpointing specific sub-groups of relevance for the education sector. This is a deficiency of the model because all kinds of student categories within those receiving study loans in extraordinary circumstances are treated as an anonymous mass. Therefore, further research should preferably focus on developing algorithms for certain sections of the students affected by the application of the model. 
The analytic treatment of data consisted of the usage of numerical values in the developed expression. The methods used support their analytic burdens due to Equation (2) mirroring the reality that is to be influenced. The methods are robust to violations of the assumptions that underlie them and provide clear insights into the data. Ancillary analyses for statistical error rates are less important to perform in this study because basic and easily available data were used throughout. Interventions or experimental manipulations were not used. The object groups of interest were approached in an impersonal way and not directly affected during the performance of the work.

The correctness of the calculations in Equations (2) and (3) plus realistic outcome from the case studies demonstrate the reliability of this study. The study's validity is shown by the use of common economic theory as basis for this work.

\section{Conclusion}

The NORDIC model can be used to reduce the dropout rate in a nation. The education model presented enhances the qualification age of the students by employing the NORDIC model in a societal context to improve welfare.

This work contributes to the literature by providing novel solutions to promote passed exams and students' wellbeing, and to improve the school authorities' performance. An improvement in management practices, mainly in a nation's public sector, is this paper's main contribution to scientific knowledge. These findings also impact the private education sector.

The main finding from this study was that the NORDIC model represented a versatile theory to improve the education in entities, such as nations, which subsequently experienced a reduced burden, in economic and social terms. The evidence for this statement was in the results of this case study based on real world data. The novelty of my approach was the innovative usage of shadow costs to create economic incentives to improve the education.

The introduction of a single key indicator $\left(S_{\text {dropout }}\right)$ to monitor most aspects of interest for students was a major highlight of this work. The most interesting findings from this study were methods to facilitate school managers' policy decisions, and the positive impact of the launched methodology on the study situation as expressed by the $L$-factor in Equation (2). This was also a major, or key attributing, factor of this work.

\subsection{Benefits}

1) Personal suffering would be reduced due to the decreased qualification age of the students.

2) School authorities obtain a versatile tool to decrease the dropout rate.

3) Employing combined methods based on common economic and mathematic theories. 


\subsection{Recommendation}

I recommend applying the NORDIC model to education issues and employing the NORDIC model to decrease the dropout rate and lower the qualification age of the students.

\section{Funding}

This research received no specific grant from funding agencies in the public, commercial, or not-for-profit sectors.

\section{Conflicts of Interest}

The author declares no conflicts of interest regarding the publication of this paper.

\section{The Author's Contribution to the Present Study}

J Stenis-Concept idea, planning of the work, performance of the literature study, methodology design, NORDIC model development, all the research effort, all the writing of the paper.

\section{References}

Beckne, R. (1995). Dropouts in the Swedish School: A Follow-Up Study of an Age Group of Students from 10-26 Years of Age. Stockholm: Stockholm University Press. (In Swedish)

Budgen, C., \& Gamroth, L. (2008). An Overview of Practice Education Models. Nurse Education Today, 28, 273-283. https://doi.org/10.1016/j.nedt.2007.05.005

Csermely, P., Korlevic, K., \& Sulyouk, K. (2006). Science Education Models and Networking of Student Research Training under 21. In NATO Advanced Research Workshop on Science Education: Talent Recruitment and Public Understanding. Washington DC: IOS Press.

CSN (2020). Aid Paid out to Those Who Got Study Loans in Excess of the Weekly Limits (240 Weeks) in 2018, Swedish: Utbetalt belopp till de som fät studiemedel över veckogränserna (240 veckor) under 2018. CSN Datawarehouse, Delivery File Registration No. ADM/2020:153, Data on Request by CSN, March 2, 2020. (In Swedish)

de Bruin, A. B. H., Smits, N., Rikers, R. M. J. P., \& Schmidt, H. G. (2008). Deliberate Practice Predicts Performance over Time in Adolescent Chess Players and Drop-Outs: A Linear Mixed Models Analysis. British Journal of Psychology, 99, 473-497. https://doi.org/10.1348/000712608X295631

Dropping Out (2020). In Wikipedia, the Free Encyclopedia. https://en.wikipedia.org/wiki/Dropping_out

Ekonomifakta (2020a). The Nation's Public Budget, Swedish: Statsbudgeten. (In Swedish) https://www.ekonomifakta.se

Ekonomifakta (2020b). Qualification Age, Swedish: Examensålder. (In Swedish) https://www.ekonomifakta.se/fakta/utbildning-och-forskning/utbildningsniva/examen salder

Fedorov, A. (2011). Modern Media Education Models. Acta Didactica Napocensia, 4, 
73-82.

Fedorov, A. (2014). Russian and Western Media Literacy Education Models. European Researcher, 73, 764-780. (In Russian) https://doi.org/10.13187/issn.2219-8229

Gray, C. C., \& Perkins, D. (2019). Utilizing Early Engagement and Machine Learning to Predict Student Outcomes. Computers \& Education, 131, 22-32. https://doi.org/10.1016/j.compedu.2018.12.006

Gupta, S. K., Antony, J., Lacher, F., \& Douglas, J. (2020). Lean Six Sigma for Reducing Student Dropouts in Higher Education-An Exploratory Study. Total Quality Management \& Business Excellence, 31, 178-193. https://doi.org/10.1080/14783363.2017.1422710

Horowitz, T. R. (1992). Dropout-Mertonian or Reproduction Scheme? Adolescence, 27, 451-459. https://doi.org/10.1023/A:1018789320129

Iemmi, V., Gibson, L., Blanchet, K., Kumar, S., Rath, S., Hartley, S., Murthy, G., Patel, V., Weber, J., \& Kuper, H. (2015). Community-Based Rehabilitation for People with Disabilities in Low- and Middle-Income Countries: A Systematic Review. Campbell Systematic Reviews, 11, 1-177. https://doi.org/10.4073/csr.2015.15

Kim, D., \& Kim, S. (2018). Sustainable Education: Analyzing the Determinants of University Student Dropout by Nonlinear Panel Data Models. Sustainability, 10, 954-972. https://doi.org/10.3390/su10040954

Longden, B., \& Mantz, Y. (2004). Retention and Student Success in Higher Education. Maidenhead: McGraw-Hill Education.

Morphew, C., \& Baker, B. (2007). On the Utility of National Datasets and Resource Cost Models for Estimating Faculty Instructional Costs in Higher Education. Journal of Education Finance, 33, 20-48.

Napoli, A. R., \& Wortman, P. M. (1998). Psychosocial Factors Related to Retention and Early Departure of Two-Year Community College Students. Research in Higher Education, 39, 419-455. https://doi.org/10.1023/A:1018789320129

Noh, M., Lee, Y., \& Kenward, M. G. (2011). Robust Estimation of Dropout Models Using Hierarchical Likelihood. Journal of Statistical Computation and Simulation, 81, 693-706. https://doi.org/10.1080/00949650903467898

Perchinunno, P., Bilancia, M., \& Vitale, D. (2019). A Statistical Analysis of Factors Affecting Higher Education Dropouts. Social Indicators Research, 12/19/2019. https://doi.org/10.1007/s11205-019-02249-y

Periwal, N., \& Rana, K. (2017). An Empirical Comparison of Models for Dropout Prophecy in MOOCs. In International Conference on Computing, Communication and Automation (pp. 906-911). Dehradun: Berkely Electronic Press.

https://doi.org/10.1109/CCAA.2017.8229935

SCB (2020b). Sweden's GDP, Swedish: Sveriges BNP. (In Swedish) https://www.scb.se/hitta-statistik/sverige-i-siffror/samhallets-ekonomi/bnp-i-sverige

Shadow Price (2020). In Wikipedia, the Free Encyclopedia. https://en.wikipedia.org/wiki/Shadow_price

Statistics Sweden (SCB) (2020a). Costs for the Educational System 2014-2018. Official Statistics of Sweden. Statistical Reports. UF 12 SM 1901, Swedish: Kostnader för utbildningsväsendet 2014-2018. Sveriges officiella statistik. Statistiska meddelanden. UF 12 SM 190. (In Swedish)

https://www.scb.se/contentassets/c1c800f27cae4b12894d379ef1bf6bb1/uf0514_2018a01 sm_ufsmsm1901.pdf

Stenis, J. (2020a). An Economic Instrument to Improve Migration. Applied Economics 
and Finance, 7, 15-20. https://doi.org/10.11114/aef.v7i1.4630

Stenis, J. (2020b). Application of the NORDIC Model to Improve the Workforce in Sweden. Applied Economics and Finance, 7, 18-23. https://doi.org/10.11114/aef.v7i2.4711

Stenis, J., \& Hogland, W. (2019). An Economic Instrument to Improve Communities. Theoretical Economics Letters, 9, 1804-1816. https://doi.org/10.4236/tel.2019.96115

Verzilli, C. J., \& Carpenter, J. R. (2002). A Monte Carlo EM Algorithm for Random-Coefficient-Based Dropout Models. Journal of Applied Statistics, 29, 1011-1021. https://doi.org/10.1080/0266476022000006711

Wankel, C., Blessinger, P., Stanaityte, J., \& Washington, N. (2013). Increasing Student Engagement and Retention Using Classroom Technologies Classroom Response Systems and Mediated Discourse Technologies. Bingley: Emerald.

https://doi.org/10.1108/S2044-9968(2013)6_Part_E 